\title{
Letter to the editor: Early transmission dynamics of Ebola virus disease (EVD), West Africa, March to August 2014 - Eurosurveillance 17 September 2014
}

D Plachouras (diamantis.plachouras@ecdc.europa.eu) ${ }^{1}$, B Sudre ${ }^{1}$, M Testa $^{1}$, E Robesyn ${ }^{1}$, D Coulombier ${ }^{1}$

1. European Centre for Disease Prevention and Control (ECDC), Stockholm, Sweden

Citation style for this article:

Plachouras D, Sudre B, Testa M, Robesyn E, Coulombier D. Letter to the editor: Early transmission dynamics of Ebola virus disease (EVD), West Africa, March to August 2014 - Eurosurveillance 17 September 2014. Euro Surveill. 2014;19(37):pii=20907. Available online: http://www.eurosurveillance.org/ViewArticle. aspx?Articleld $=20907$

Article submitted on 17 September 2014 / published on 18 September 2014

\section{To the editor:}

In their article Early transmission dynamics of Ebola virus disease (EVD), West Africa, March to August 2014, published on 11 September, Nishiura and Chowell estimated the effective reproductive number Rt for the mainly affected countries, Guinea, Liberia and Sierra Leone, to be consistently above 1 since June 2014 , indicating that the outbreak is not yet under control [1]. Such studies are welcome and useful to understand and quantify the ongoing epidemic and to plan the response activities.

However, we would like to add a cautionary note to the interpretation of the surveillance data. Important detailed information may be missed by such general modelling approach. The study of the epidemic curves based on data retrieved by week and district of reporting, from the situational reports of the Ministry of Health of Liberia [2] shows very different patterns contributing to the overall observed dynamic at national level. Figure 1 shows the number of suspected, probable and confirmed cases reported by week in Liberia,

\section{FIGURE 1}

Distribution of suspected, probable and confirmed cases of Ebola virus disease by week of reporting, Liberia, week 21 (starting on 19 May) to 37 (starting on 8 September) $2014(\mathrm{n}=2,663)$

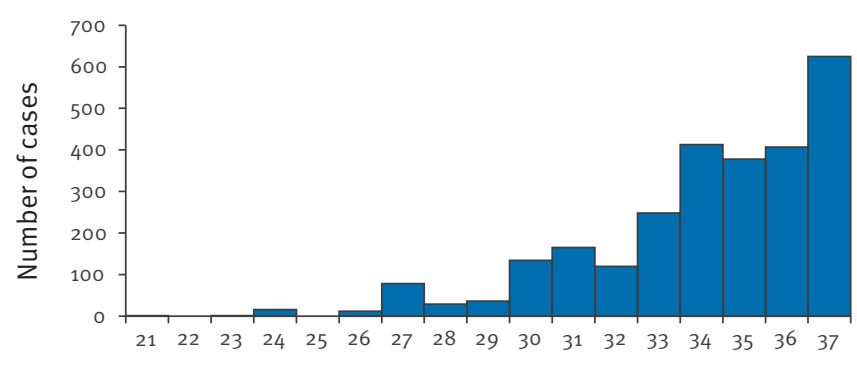

Week 2014 from calendar week 21 (starting on 19 May) to week 37 (starting on 8 September) 2014. Following the steep increase in the number of cases up to week 34, which was described by Nishiura and Chowell, a levelling off in the number of newly reported cases occurred between weeks 34 and 36 resulting in the flattening of the curve, followed by a new increase in week 37 .

Figure 2 shows the distribution of newly reported cases by week for selected districts of Liberia. Only districts that reported more than five cases since the start of the epidemic are shown. The epidemic curves show markedly different patterns. The districts of Bomi, Bong, Grand Cape Mount, Margibi and Nimba experienced a relatively stable number of weekly cases, while the districts of Lofa and Grand Bassa reported an increase in the number of cases up to weeks 33 and 35 , respectively, followed by a decrease in subsequent weeks. The district of Montserrado shows a continuous increasing pattern from week 29 up to week 37.

The presentation of aggregated data for Liberia at national level which shows a transient overall stabilising and even slightly decreasing trend in the number of newly reported cases between weeks 34 and 36 can therefore be misleading. The alarming trend in the district of Montserrado is compensated by a decreasing trend observed in the recent weeks in districts reporting fewer cases.

Furthermore, the observed dynamic based on available surveillance data can only be interpreted in the light of the performance of the surveillance system having generated them. There are reports from areas in the affected countries where hospitals have closed, health centres are overwhelmed, patients are treated at home and contact tracing and monitoring is inadequate. Caution is therefore necessary when interpreting the data, as a decrease in the number of newly reported cases could signify either a positive effect of the interventions to control the epidemic or a decrease in the 


\section{FIGURE 2}

Distribution of newly reported cases of Ebola virus disease by week and selected districts, Liberia, week 21 (starting on 19 May) to 37 (starting on 8 September) 2014
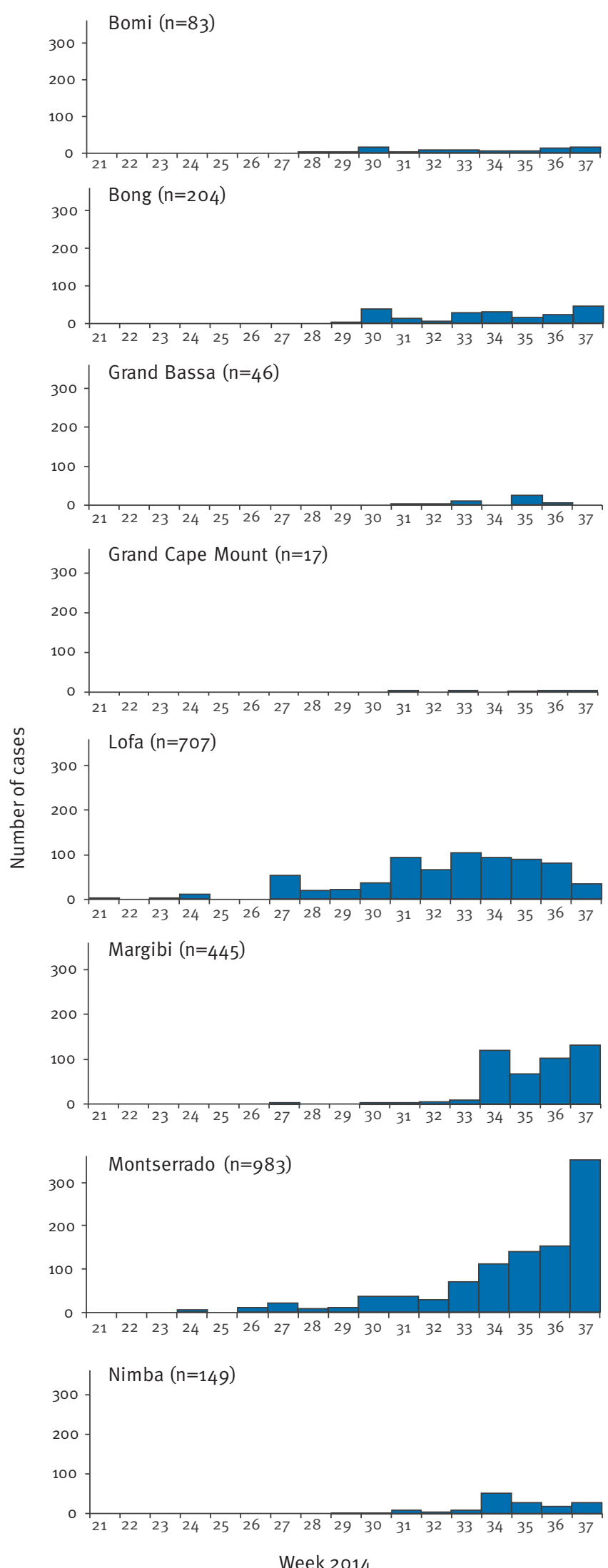

performance of the surveillance system. Similarly, an increase in the number of cases could result not only from improved surveillance but also from increased transmission.

The use of surveillance data for setting priority intervention areas, for measuring their effectiveness and for planning resources on the basis of forecasting, needs to consider the performance of the surveillance system through which the data are generated. Simple surveillance quality indicators should be collected along with epidemiological data, such as the number of contacts identified and monitored. Moreover, studies assessing performance are a useful addition to allow better understanding of the limitation of surveillance data, e.g. capture-recapture studies, review of healthcare facilities records or household visits in affected areas. In conclusion, ensuring efficient surveillance is essential for the effective response to this devastating outbreak.

\section{References}

1. Nishiura H, Chowell G. Early transmission dynamics of Ebola virus disease (EVD), West Africa, March to August 2014. Euro Surveill. 2014;19(36): pii=20894.

2. Ministry of Health and Social Welfare, Liberia. Liberia Ebola Situation Reports 2014. Monrovia: Ministry of Health and Social Welfare. Available from: http://www.mohsw.gov.lr/ content_display.php?press_id=118\&sub=press_release 